\title{
BILANGAN B-KROMATIK PADA GRAF ORIGAMI, GRAF LINTANG, DAN GRAF TADPOLE
}

\author{
Pranasari Kornelia, Evi Noviani, Fransiskus Fran
}

\section{INTISARI}

Pewarnaan b-colouring pada graf $G$ adalah pewarnaan simpul-simpul $G$, sedemikian sehingga terdapat minimal satu simpul pada setiap kelas warna bertetangga dengan setidaknya satu simpul pada setiap kelas warna lainnya. Jumlah warna maksimum yang digunakan pada pewarnaan b-colouring di graf $G$ disebut dengan bilangan b-kromatik yang dinotasikan dengan $\varphi(G)$. Pada penelitian ini dibahas tentang bilangan b-kromatik pada graf origami, graf lintang, dan graf tadpole. Graf origami (dinotasikan dengan $O_{n}$ ) merupakan graf dengan pusat berupa cycle dengan $n$ simpul dan lipatan-lipatan yang dibentuk dari penggabungan dua buah cycle $C_{3}$, sedangkan graf lintang (dinotasikan dengan $L_{m}$ ) terbentuk dari 2 simpul kutub dan $m$ simpul lintang, dan graf tadpole (dinotasikan dengan $T_{m, n}$ ) terbentuk dari graf lintasan dengan $n$ simpul dan graf cycle dengan $m$ simpul. Berdasarkan penelitian diperoleh bilangan $b$ kromatik pada graf origami yaitu 4 untuk $n=3$ dan $n=4,5$ untuk $n=5$, dan 6 untuk $n \geq 6$. Bilangan bkromatik pada graf lintang yaitu 2 untuk $m \geq 2$ dan bilangan $b$-kromatik pada graf tadpole yaitu 3 untuk $m \geq 3$ dan $n \geq 2$.

Kata Kunci: b-colouring, graf origami, graf lintang, graf tadpole.

\section{PENDAHULUAN}

Salah satu pembahasan dalam teori graf yang hingga kini masih menjadi topik yang menarik untuk dikaji yaitu tentang pewarnaan graf. Pewarnaan graf $G$ merupakan pemetaan warna-warna ke simpul maupun sisi sehingga setiap simpul yang bertetangga atau sisi yang bersisian memiliki warna yang berbeda. Pewarnaan pada graf dibagi dalam tiga bagian yaitu pewarnaan simpul, pewarnaan sisi, dan pewarnaan bidang.

Konsep pewarnaan b-colouring merupakan pengembangan dari pewarnaan simpul [1]. Pada penelitian [1], diperoleh pula konsep penentuan bilangan $b$-kromatik pada suatu graf. Pewarnaan $b$ colouring pada graf $G$ adalah pewarnaan simpul-simpul pada graf $G$, sedemikian sehingga terdapat simpul di setiap kelas warna yang bertetangga dengan setidaknya satu simpul di kelas warna lainnya, simpul ini disebut juga simpul yang mendominasi [2]. Adapun definisi dari bilangan $b$-kromatik (dinotasikan dengan $(\varphi(G)$ ), didefinisikan sebagai jumlah maksimum dari $k$ warna yang dapat digunakan untuk mewarnai simpul dari $G$ dengan pewarnaan $b$-colouring [3].

Pewarnaan $b$-colouring memiliki beberapa aplikasi, salah satunya yaitu pada penelitian yang membahas penggunaan konsep pewarnaan $b$-colouring pada kerangka kerja pengelompokkan data. Pada penelitian tersebut, disajikan kerangka kerja baru pewarnaan b-colouring graf untuk mengelompokkan objek-objek heterogen ke dalam kelompok-kelompok [4]. Selain aplikasi, masalah yang banyak dikaji tentang pewarnaan $b$-colouring adalah menentukan bilangan $b$-kromatik pada beberapa graf diantaranya bilangan $b$-kromatik pada graf matahari, graf barbel, dan beberapa graf lainnya [5]. Terkait hal tersebut, maka perlu dilakukan penelitian lebih lanjut mengenai objek graf lainnya.

Graf origami, graf lintang, dan graf tadpole menarik untuk dibahas karena merupakan pengembangan dari graf-graf pembangun yaitu graf lintasan dan cycle. Graf origami merupakan graf dengan pusat berupa graf cycle dan lipatan-lipatan origami yang merupakan penggabungan dari dua buah graf cycle $C_{3}$. Graf lintang terbentuk dari graf lintasan dan graf cycle, sedangkan graf tadpole 
terbentuk dari penggabungan graf cycle dan graf lintasan. Sementara itu, penelitian terkait bilangan $b$ kromatik pada ketiga graf tersebut belum pernah dibahas oleh peneliti lainnya.

Terkait hal tersebut, maka akan dilakukan penelitian bilangan $b$-kromatik pada graf origami, graf lintang, dan graf tadpole. Namun sebelumnya akan dikaji terlebih dahulu bilangan $b$-kromatik pada graf yang membangun graf-graf tersebut yaitu bilangan $b$-kromatik pada graf lintasan dan cycle.

\section{PEWARNAAN GRAF}

Graf $G$ didefinisikan sebagai pasangan himpunan $(V, E)$, ditulis dengan notasi $G=(V, E)$, yang dalam hal ini $V$ adalah himpunan tidak kosong dari simpul-simpul (vertices atau node) dan $E$ adalah himpunan sisi (edges atau arc) yang menghubungkan sepasang simpul. Adapun graf yang dibahas yaitu graf yang berkaitan dengan graf lintasan dan graf cycle.

Graf lintasan adalah graf yang terdiri dari sebuah lintasan tunggal. Graf lintasan dengan $n$ simpul dilambangkan dengan $P_{n}$ [7]. Adapun contoh dari graf lintasan terdapat pada Gambar 1 (a). Graf cycle adalah graf dengan $n$ simpul yang setiap simpul berderajat dua untuk $n>2$. Graf cycle dengan $n$ simpul dilambangkan dengan $C_{n}$. Jumlah simpul pada graf cycle sama dengan jumlah sisinya [8]. Adapun contoh dari graf cycle terdapat pada Gambar 1 (b). Misalkan $n \in \mathbb{N}$, graf origami $O_{n}$ dengan $3 n$ simpul adalah graf yang himpunan simpulnya $V\left(O_{n}\right)=\left\{u_{i}, v_{i}, w_{i} \mid 1 \leq i \leq n\right\}$ dan himpunan sisi $E\left(O_{n}\right)=\left\{u_{i} w_{i}, u_{i} v_{i}, v_{i} w_{i}, u_{i} u_{i+1}, w_{i} u_{i+1}, u_{1} u_{n}, u_{1} w_{n} \mid 1 \leq i \leq n\right\}$ [11]. Adapun contoh dari graf origami terdapat pada Gambar 1 (c). Komplemen dari suatu graf $G=(V, E)$ adalah graf $\bar{G}=(V, \bar{E})$, dimana sisi-sisi di $\bar{G}$ adalah sisi-sisi yang tidak ada di $G$ [10]. Graf lintang, dilambangkan dengan $L_{m}$, didefinisikan sebagai $L_{m}=\overline{K_{2}}+\overline{K_{m}}$, untuk $m \geq 1$. Andaikan graf lintang memiliki himpunan simpul $V_{1}=\left\{u_{1}, u_{2}\right\}$ sebagai simpul kutub dan $V_{2}=\left\{v_{1}, v_{2}, \ldots, v_{m}\right\}$ sebagai simpul lintang. Sementara himpunan sisi $E\left(L_{m}\right)=\left\{e_{1}, e_{2}, \ldots, e_{m}\right\}$, dimana sisi $e_{i}=v_{i} u_{1}$ dan $e_{i+m}=v_{i} u_{2}$ untuk setiap $i=1,2, \ldots, m[12]$. Adapun contoh dari graf lintang terdapat pada Gambar 1 (d). Graf yang diperoleh dengan menggabungkan cycle $C_{m}$ ke lintasan $P_{n}$, disebut graf tadpole yang dilambangkan dengan $T_{m, n}$ [13]. Adapun contoh dari graf tadpole terdapat pada Gambar 1 (e).

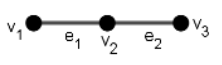

(a)

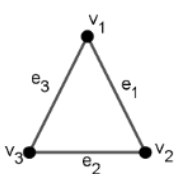

(b)

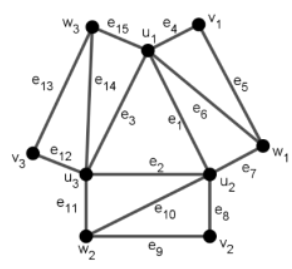

(c)

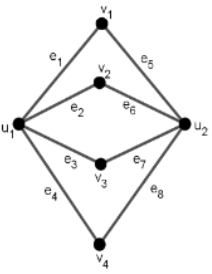

(d)

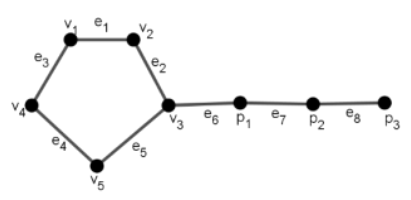

(e)

Gambar 1 (a) Graf lintasan $P_{3}$, (b) graf cycle $C_{3}$, (c) graf origami $O_{3}$, (d) graf lintang $L_{4}$, (e) graf tadpole $T_{5,3}$ 
Pewarnaan graf $G$ merupakan pemberian warna pada simpul ataupun sisi dengan batas dan aturan tertentu. Ada beberapa konsep dalam pewarnaan graf diantaranya pewarnaan simpul. Berikut dijelaskan tentang definisi dari pewarnaan simpul.

Definisi 1 [6] Misalkan $G$ adalah suatu graf dengan $V(G)$ merupakan himpunan simpul dari $G$ dan misalkan $\{1,2,3, \ldots, k\}$ merupakan himpunan semua warna yang ditetapkan untuk setiap simpul di graf $G$. Pewarnaan simpul adalah pemetaan $c: V(G) \rightarrow\{1,2,3, \ldots, k\}$ dengan $c(u) \neq c(v)$ untuk semua simpul yang bertetangga $u, v \in V(G)$.

Pada pewarnaan simpul, dapat ditentukan warna minimum yang dapat digunakan untuk mewarnai simpul-simpul pada graf yang diberikan. Adapun jumlah warna minimum tersebut diberikan pada definisi berikut.

Definisi 2 [6] Jika G dapat diwarnai dengan pewarnaan simpul maka bilangan kromatik dari G adalah jumlah warna minimum yang digunakan pada pewarnaan di graf $G$. Bilangan kromatik dinotasikan dengan $\chi(G)$.

Dari Definisi 1 dan Definisi 2 diberikan contoh pewarnaan simpul pada suatu graf berikut.

Contoh 3 Diberikan pewarnaan simpul seperti berikut:

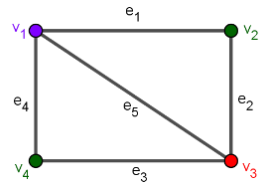

\section{Gambar 2 Pewarnaan simpul pada graf $G$}

Dari Gambar 2 pewarnaan simpul pada graf $G$ menggunakan tiga warna yang berbeda dengan tidak ada dua simpul yang bertetangga memiliki warna yang sama. Tiga warna tersebut sudah termasuk warna minimum yang digunakan pada pewarnaan simpul pada graf $G$. Adapun bilangan kromatik dari graf yang menjadi objek penelitian akan disajikan pada Tabel 1 berikut ini.

Tabel 1 Bilangan kromatik dan derajat maksimum dari graf yang menjadi objek penelitian

\begin{tabular}{|c|c|c|c|}
\hline No & Graf & $\chi(G)$ & $\Delta(G)$ \\
\hline 1 & $P_{n}$ & 2 & 2 \\
\hline 2 & \multirow{2}{*}{$C_{n}$} & 2, jika $n$ genap & \multirow{2}{*}{2} \\
\cline { 3 - 3 } & $O_{n}$ & 3 & 5 \\
\hline 3 & $L_{m}$ & 2 & $m$ \\
\hline 4 & $T_{m, n}$ & jika $n$ ganjil & \\
\cline { 3 - 3 } & \multirow{2}{*}{5} & 3ika $n$ genap & \multirow{2}{*}{3} \\
\hline
\end{tabular}

Pewarnaan $b$-colouring merupakan pewarnaan simpul dengan mempertimbangkan konsep ketetanggaan simpul [1]. Untuk lebih jelasnya, pewarnaan b-colouring akan dibahas pada bagian selanjutnya.

\section{PEWARNAAN B-COLOURING DAN BILANGAN B-KROMATIK}

Konsep pewarnaan $b$-colouring merupakan pengembangan dari pewarnaan simpul [1]. Dalam penelitian tersebut, diperkenalkan pula konsep untuk menentukan bilangan $b$-kromatik yang didefinisikan sebagai jumlah maksimum $k$ dari warna pada simpul $G$, sehingga diperoleh warna yang dapat digunakan untuk mewarnai simpul dari $G$. Adapun penjelasan dari pewarnaan $b$-colouring dijelaskan pada definisi berikut. 
Definisi 4 [2] Pewarnaan b-colouring pada graf $G$ adalah pewarnaan simpul-simpul G sedemikian sehingga terdapat suatu simpul di setiap kelas warna yang bertetangga dengan paling tidak satu simpul di masing-masing kelas warna lainnya, simpul semacam itu disebut simpul yang mendominasi.

Adapun definisi dari bilangan $b$-kromatik dijelaskan pada definisi berikut.

Definisi 5 [2] Bilangan b-kromatik dari graf $G$, dilambangkan dengan $\varphi(G)$, adalah bilangan bulat maksimal $k$ sehingga $G$ dapat diwarnai dengan pewarnaan $b$-colouring menggunakan $k$ warna.

Adapun salah satu hasil penelitian yang digunakan untuk membuktikan graf-graf yang dibahas dijelaskan pada proposisi berikut.

Proposisi 6 [9] (1) Jika G memuat b-colouring dengan $m$ warna, G harus memiliki setidaknya $m$ simpul dengan derajat setidaknya $m-1$.

(2) $\chi(G) \leq \varphi(G) \leq \Delta(G)+1$, dengan $\Delta(G)$ adalah derajat maksimum dari $G$.

Bilangan $b$-kromatik pada graf hanya dapat dicari pada graf yang terhubung. Berikut akan disajikan contoh cara mencari bilangan $b$-kromatik pada suatu graf terhubung.

Contoh 7 Diberikan graf $G$ seperti pada Gambar 3 berikut.

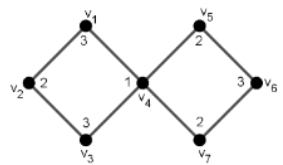

\section{Gambar 3 Pewarnaan $b$-colouring pada graf $G$ menggunakan 3 warna}

Pada Gambar 3 dapat dilihat bahwa graf $G$ merupakan $b$-colouring dan memenuhi Definisi 4 bahwa di setiap kelas warna ada simpul representatif yang bertetangga dengan setidaknya satu simpul di setiap kelas warna lainnya dan sudah merupakan pewarnaan maksimal yang digunakan. Akibatnya, maksimum kelas warna untuk pewarnaan simpul pada graf $G$ yaitu sebanyak 3 kelas warna. Dengan demikian diperoleh bilangan $b$-kromatik pada graf $G$ yaitu $\varphi(G)=3$.

Pewarnaan $b$-colouring pada graf yang dibahas adalah graf yang berkaitan dengan graf lintasan dan graf cycle. Bilangan $b$-kromatik pada graf lintasan dan cycle akan digunakan untuk mencari bilangan $b$-kromatik pada graf yang dibahas. Berikut bilangan $b$-kromatik pada graf lintasan dan cycle.

Proposisi 8 [9] Jika $P_{n}$ adalah graf lintasan dengan $n$ simpul, maka $\varphi\left(P_{2}\right)=\varphi\left(P_{3}\right)=\varphi\left(P_{4}\right)=2$ dan $\varphi\left(P_{n}\right)=3$ untuk setiap $n \geq 5$.

Selanjutnya yaitu bilangan $b$-kromatik pada graf cycle yang dijelaskan pada Proposisi 9 berikut.

Proposisi 9 [9] Jika $C_{n}$ adalah graf cycle dengan $n$ simpul, maka $\varphi\left(C_{3}\right)=3$ dan $\varphi\left(C_{4}\right)=2$, serta $\varphi\left(C_{n}\right)=3$ untuk setiap $n \geq 5$.

Selanjutnya yaitu pewarnaan $b$-colouring dari graf origami, graf lintang, dan graf tadpole akan dijelaskan pada proposisi-proposisi berikut.

Proposisi 10 Graf $G$ adalah graf origami $O_{n}$ untuk $n \geq 3$, dengan $3 n$ simpul dan $3 n$ sisi. Bilangan $b$ kromatik pada graf origami $O_{n}$ adalah:

$\varphi\left(O_{n}\right)= \begin{cases}4, & \text { jika } n=3 \text { dan } n=4 \\ 5, & \text { jika } n=5 \\ 6, & \text { jika } n \geq 6\end{cases}$

Bukti: Misalkan graf $G$ adalah graf origami $O_{n}$ untuk $n \geq 3$, dengan $3 n$ simpul dan $3 n$ sisi. Misalkan $u_{i}, v_{i}, w_{i} \in V\left(O_{n}\right), i=1,2, \ldots, n$. Berdasarkan Proposisi 6, terdapat empat kasus bilangan $b$-kromatik pada graf $O_{n}$. 
1) Untuk $n=3$

Graf $O_{3}$ memiliki tiga simpul berderajat 5, tiga simpul berderajat 3, dan tiga simpul berderajat 2 . Berdasarkan ketaksamaan pada Proposisi 6 dan Tabel 1 diperoleh $3 \leq \varphi\left(O_{n}\right) \leq 6$. Selanjutnya didefinisikan pewarnaan simpul yaitu:

$$
\begin{aligned}
& c\left(u_{1}\right)=c\left(v_{2}\right)=c\left(v_{3}\right)=1, \\
& c\left(u_{2}\right)=c\left(w_{3}\right)=2, \\
& c\left(u_{3}\right)=c\left(w_{1}\right)=3, \text { dan } \\
& c\left(v_{1}\right)=c\left(w_{2}\right)=4 .
\end{aligned}
$$

Akibatnya terdapat simpul perwakilan pada setiap kelas warna yaitu simpul $u_{1}$ untuk kelas warna $C_{1}$, simpul $u_{2}$ untuk kelas warna $C_{2}$, simpul $u_{3}$ dan $w_{1}$ untuk kelas warna $C_{3}$, dan simpul $w_{2}$ untuk kelas warna $C_{4}$. Oleh karena itu, berdasarkan Definisi 4 pewarnaan tersebut merupakan pewarnaan $b$ colouring, sehingga diperoleh $\varphi\left(O_{3}\right) \geq 4$. Lebih lanjut, misalkan $\varphi\left(O_{3}\right)=5$, maka berdasarkan Proposisi $6 \mathrm{O}_{3}$ harus memiliki minimal lima simpul berderajat 4. Hal tersebut kontradiksi, karena $\mathrm{O}_{3}$ tidak memiliki simpul berderajat 4. Jadi haruslah $\varphi\left(O_{3}\right)=4$.

2) Untuk $n=4$

Graf $\mathrm{O}_{4}$ memiliki empat simpul berderajat 5, empat simpul berderajat 3, dan empat simpul berderajat 2. Berdasarkan ketaksamaan pada Proposisi 6 dan Tabel 1 diperoleh $3 \leq \varphi\left(O_{n}\right) \leq 6$. Selanjutnya didefinisikan pewarnaan simpul yaitu:

$$
\begin{aligned}
& c\left(u_{1}\right)=c\left(v_{2}\right)=c\left(v_{3}\right)=1, \\
& c\left(u_{2}\right)=c\left(v_{4}\right)=c\left(w_{3}\right)=2, \\
& c\left(u_{3}\right)=c\left(w_{1}\right)=c\left(w_{4}\right)=3, \text { dan } \\
& c\left(u_{4}\right)=c\left(v_{1}\right)=c\left(w_{2}\right)=4 .
\end{aligned}
$$

Akibatnya terdapat simpul perwakilan pada setiap kelas warna yaitu simpul $u_{1}$ untuk kelas warna $C_{1}$, simpul $u_{2}$ dan $w_{3}$ untuk kelas warna $C_{2}$, simpul $u_{3}, w_{1}$ dan $w_{4}$ untuk kelas warna $C_{3}$, dan simpul $u_{4}$ dan $w_{2}$ untuk kelas warna $C_{4}$. Oleh karena itu, berdasarkan Definisi 4 pewarnaan tersebut merupakan pewarnaan $b$-colouring, sehingga diperoleh $\varphi\left(O_{4}\right) \geq 4$. Selanjutnya misalkan $\varphi\left(O_{4}\right)=5$, maka berdasarkan Proposisi $6 \mathrm{O}_{4}$ harus memiliki minimal lima simpul berderajat 4 . Hal tersebut kontradiksi, karena $O_{4}$ tidak memiliki simpul berderajat 4. Jadi haruslah $\varphi\left(O_{4}\right)=4$.

3) Untuk $n=5$

Graf $O_{5}$ memiliki lima simpul berderajat 5, lima simpul berderajat 3, dan lima simpul berderajat 2. Berdasarkan ketaksamaan pada Proposisi 6 dan Tabel 1 diperoleh $3 \leq \varphi\left(O_{n}\right) \leq 6$. Selanjutnya misalkan pewarnaan simpul yaitu: $c\left(u_{i}\right)=i$, dengan $i=1,2,3,4$, dan 5 , serta warnai simpul $v_{i}$ dan $w_{i}$ menggunakan warna $1,2,3,4$, atau 5 , sehingga pewarnaan $c$ merupakan pewarnaan $b$-colouring, sehingga terdapat simpul perwakilan pada setiap kelas warna. Adapun simpul-simpul perwakilannya yaitu simpul $u_{1}$ untuk kelas warna $C_{1}$, simpul $u_{2}$ untuk kelas warna $C_{2}$, simpul $u_{3}$ untuk kelas warna $C_{3}$, simpul $u_{4}$ untuk kelas warna $C_{4}$, dan simpul simpul $u_{5}$ untuk kelas warna $C_{5}$. Oleh karena itu, berdasarkan Definisi 4 pewarnaan tersebut merupakan pewarnaan $b$-colouring, sehingga diperoleh $\varphi\left(O_{5}\right) \geq 5$. Selanjutnya andaikan $\varphi\left(O_{5}\right)=6$, maka berdasarkan Proposisi $6 O_{5}$ harus memiliki minimal enam simpul berderajat 5 . Hal tersebut kontradiksi, karena $O_{5}$ memiliki maksimal lima simpul berderajat 5. Jadi haruslah $\varphi\left(O_{5}\right)=5$.

4) Untuk $n \geq 6$

Graf $O_{n \geq 6}$ memiliki $n$ simpul berderajat 5, $n$ simpul berderajat 3, dan $n$ simpul berderajat 2 . Berdasarkan ketaksamaan pada Proposisi 6 dan Tabel 1 diperoleh $3 \leq \varphi\left(O_{n}\right) \leq 6$. Selanjutnya didefinisikan pewarnaan simpul yaitu: 
$c\left(u_{i}\right)= \begin{cases}1, & i=6 k-5 \\ 2, & i=6 k-4 \\ 3, & i=6 k-3 \\ 4, & i=6 k-2 \\ 5, & i=6 k-1 \\ 6, & i=6 k\end{cases}$

dengan $k \in \mathbb{N}$ sehingga $i=1,2, \ldots, n$, serta warnai simpul $v_{i}$ dan $w_{i}$ menggunakan warna $1,2,3,4,5$, atau 6 , sehingga pewarnaan $c$ merupakan pewarnaan $b$-colouring, sehingga terdapat simpul perwakilan pada setiap kelas warna. Adapun simpul-simpul perwakilannya yaitu simpul $u_{6 k-5}$ untuk kelas warna $C_{1}$, simpul $u_{6 k-4}$ untuk kelas warna $C_{2}$, simpul $u_{6 k-3}$ untuk kelas warna $C_{3}$, simpul $u_{6 k-2}$ untuk kelas warna $C_{4}$, simpul $u_{6 k-1}$ untuk kelas warna $C_{5}$ dan simpul simpul $u_{6 k}$ untuk kelas warna $C_{6}$. Oleh karena itu, berdasarkan Definisi 4 pewarnaan tersebut merupakan pewarnaan $b$ colouring. Selanjutnya berdasarkan definisi bilangan $b$-kromatik diperoleh $\varphi\left(O_{n \geq 6}\right) \geq 6$. Lebih lanjut, andaikan $\varphi\left(O_{n \geq 6}\right)=7$, maka berdasarkan Proposisi $6 O_{n \geq 6}$ harus memiliki minimal tujuh simpul berderajat 6 . Hal tersebut kontradiksi karena $O_{n \geq 6}$ hanya memiliki simpul yang maksimal berderajat 5 . Jadi haruslah $\varphi\left(O_{n \geq 6}\right)=6$.

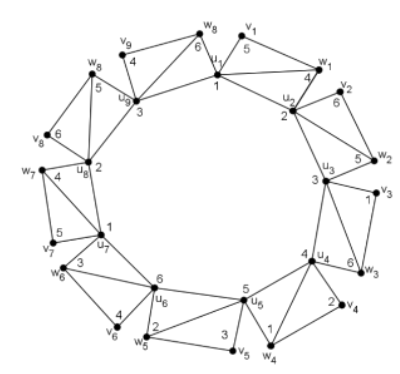

\section{Gambar 4 Pewarnaan b-colouring pada graf origami $O_{9}$}

Proposisi 11 Graf lintang didefinisikan sebagai $L_{m}=\overline{K_{2}}+\overline{K_{m}}$, untuk $m \geq 1$. Bilangan b-kromatik pada graf lintang $L_{m}$ adalah 2 .

Bukti: Misalkan graf $G$ adalah graf lintang $L_{m}=\overline{K_{2}}+\overline{K_{m}}$, dengan $u_{i} \in V\left(\overline{K_{2}}\right), i=1,2$ sebagai simpul kutub dan $v_{i} \in V\left(\overline{K_{m}}\right), i=1,2, \ldots, m$ sebagai simpul lintang. Berdasarkan Tabel 1 diperoleh bilangan kromatik dari graf lintang yaitu $\chi\left(L_{m}\right)=2$. Akibatnya berdasarkan Proposisi 6 maka diperoleh $\varphi\left(L_{m}\right) \geq 2$. Selanjutnya andaikan $\varphi\left(L_{m}\right)=3$, dengan pewarnaan simpul yaitu $c\left(u_{1}\right)=1, c\left(v_{i}\right)=2$, dan $c\left(u_{2}\right)=3$. Pada pewarnaan tersebut terdapat simpul perwakilan yaitu simpul $v_{i}$ untuk kelas warna $C_{2}$, tetapi tidak ada simpul perwakilan untuk kelas warna $C_{1}$ dan $C_{3}$. Hal tersebut kontradiksi berdasarkan Definisi 2.1 tentang pewarnaan $b$-colouring. Jadi haruslah $\varphi\left(L_{m}\right)=2$.

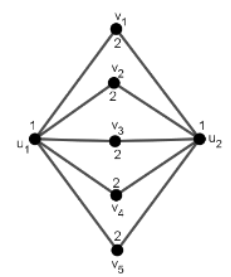

\section{Gambar 5 Pewarnaan b-colouring pada graf lintang $L_{5}$}

Proposisi 12 Graf $G$ adalah graf tadpole $T_{m, n}$, dengan $m \geq 3$ dan $n \geq 2$. Bilangan b-kromatik pada graf tadpole $T_{m, n}$ adalah 3 .

Bukti: Graf tadpole diperoleh dengan menggabungkan graf cycle $C_{m}$ ke lintasan $P_{n}$. Misalkan $c_{i} \in V\left(C_{m}\right), i=1,2, \ldots, n$ dan $p_{j} \in V\left(P_{n}\right), j=1,2, \ldots, n$ adalah himpunan semua simpul pada graf tadpole $T_{m, n}$ dengan satu simpul berderajat 3 dan 1 , sedangkan simpul yg lainnya berderajat 2 , 
sehingga diperoleh $\Delta\left(T_{m, n}\right)=3$. Berdasarkan Tabel 1 diketahui $\chi\left(T_{m, n}\right)=2$ untuk $m$ genap dan $\chi\left(T_{m, n}\right)=3$, untuk $m$ ganjil.

Berdasarkan ketaksamaan $\chi(G) \leq \varphi(G) \leq \Delta(G)+1$ pada Proposisi 6 dan Tabel 1 maka diperoleh $2 \leq \varphi\left(T_{m, n}\right) \leq 4$ untuk $m$ genap dan $3 \leq \varphi\left(T_{m, n}\right) \leq 4$ untuk $m$ ganjil. Dengan demikian terdapat dua kasus bilangan $b$-kromatik pada $T_{m, n}$.

1) Untuk $m$ ganjil

Berdasarkan ketaksamaan pada Proposisi 6 diperoleh $\varphi\left(T_{m, n}\right) \geq 3$. Andaikan $\varphi\left(T_{m, n}\right)=4$, maka $T_{m, n}$ harus memiliki minimal 4 simpul berderajat 3 . Hal tersebut kontradiksi karena $T_{m, n}$ hanya memiliki satu simpul berderajat 3 . Akibatnya $\varphi\left(T_{m, n}\right) \neq 4$. Jadi haruslah $\varphi\left(T_{m, n}\right)=3$.

2) Untuk $m$ genap

Berdasarkan ketaksamaan diperoleh $\varphi\left(T_{m, n}\right) \geq 2$. Selanjutnya didefinisikan pewarnaan pada graf $T_{m, n}$ sebagai berikut:

$c\left(c_{i}\right)=\left\{\begin{array}{ll}1, & i=3 k-2 \\ 2, & i=3 k-1 \\ 3, & i=3 k\end{array} \quad\right.$ dan $\quad c\left(p_{j}\right)= \begin{cases}1, & j=3 k \\ 2, & j=3 k-1 \\ 3, & j=3 k-2\end{cases}$

dengan $k \in \mathbb{N}$, sehingga $i=1,2, \ldots m$ dan $j=1,2, \ldots n$

Akibatnya diperoleh himpunan kelas warna yaitu:

$C_{1}=\left\{c_{1}, c_{4}, \ldots, c_{3 k-2}, p_{3}, p_{6}, \ldots, p_{3 k}\right\}$,

$C_{2}=\left\{c_{2}, c_{5}, \ldots, c_{3 k-1}, p_{2}, p_{5}, \ldots, p_{3 k-1}\right\}$,

$C_{3}=\left\{c_{3}, c_{6}, \ldots, c_{3 k}, p_{1}, p_{4}, \ldots, p_{3 k-2}\right\}$.

Berdasarkan kelas warna $C_{1}, C_{2}$, dan $C_{3}$ maka terdapat simpul perwakilan pada setiap kelas warna yang bertetangga dengan setidaknya satu simpul pada setiap kelas warna lainnya. Oleh karena itu, pewarnaan yang didefinisikan merupakan pewarnaan $b$-colouring. Akibatnya diperoleh $\varphi\left(T_{m, n}\right) \geq 3$. Selanjutnya andaikan $\varphi\left(T_{m, n}\right)=4$, maka $T_{m, n}$ harus memiliki minimal empat simpul berderajat 3 . Hal tersebut kontradiksi karena $T_{m, n}$ hanya memiliki satu simpul berderajat 3 . Akibatnya $\varphi\left(T_{m, n}\right) \neq 4$. Jadi haruslah $\varphi\left(T_{m, n}\right)=3$.

Dari kasus 1) dan 2) tersebut dapat disimpulkan bahwa bilangan $b$-kromatik pada graf tadpole $\varphi\left(T_{m, n}\right)=3$, untuk $m \geq 3$ dan $n \geq 2$.

Sebagai ilustrasi dari pewarnaan $b$-colouring pada graf tadpole $T_{m, n}$, untuk $m$ ganjil dan $m$ genap dengan 3 warna disajikan pada Contoh 6 berikut.

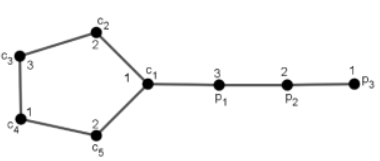

(a)

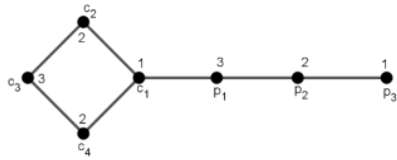

(b)

Gambar 6 Pewarnaan $b$-colouring pada (a) graf tadpole $T_{5,3}$ dan (b) graf tadpole $T_{4,3}$

Pada Gambar 6 graf tadpole $T_{m, n}$, untuk $m$ ganjil yaitu $T_{5,3}$ dan $m$ genap yaitu $T_{4,3}$ diwarnai dengan pewarnaan $b$-colouring menggunakan 3 warna.

\section{KESIMPULAN}

Bilangan $b$-kromatik pada graf origami, graf lintang, dan graf tadpole diperoleh dari pewarnaan $b$ colouring. Adapun proses untuk mencari bilangan $b$-kromatik dimulai dengan menggambar dan mewarnai simpul-simpul pada ketiga graf tersebut berdasarkan konsep $b$-colouring. Kemudian menentukan banyaknya warna maksimum yang digunakan untuk mewarnai simpul-simpul sehingga diperoleh pola bilangan pada ketiga graf tersebut. Berdasarkan proses-proses tersebut, maka dapat disimpulkan bilangan $b$-kromatik pada graf origami, graf lintang, dan graf tadpole, yaitu: 
a. Bilangan $b$-kromatik pada graf origami $O_{n}$

b. Bilangan $b$-kromatik pada graf lintang $L_{m}$

$$
\varphi\left(O_{n}\right)= \begin{cases}4, & \text { jika } n=3 \text { dan } n=4 \\ 5, & \text { jika } n=5 \\ 6, & \text { jika } n \geq 6\end{cases}
$$

c. Bilangan $b$-kromatik pada graf tadpole $T_{m, n}$

$$
\varphi\left(L_{m}\right)=2 \text {, dengan } m \geq 1
$$

$$
\varphi\left(T_{m, n}\right)=3 \text {, dengan } m \geq 3 \text { dan } n \geq 2 .
$$

\section{DAFTAR PUSTAKA}

[1] Irving WR dan Manlove FD. The B-chromatic Number of A Graph. Discrete Applied Mathematics. 1999; 91: 127-141.

[2] Sahili AE dan Kouider M. About b-colouring of Regular Graphs. Article in Utilitas Mathematica-November 2009. 2009.

[3] Kok J dan Sudev N. The b-chromatic Number of Certain Graphs and Digraphs. math. GM. 2015; 1511.00680vl.

[4] Elghazel H, Kheddouchi H, Deslandres V dan Dussauchoy A. A Graph b-colouring Framework for Data Clustering. Jurnal Math Algor. 2008; 7: 389-423.

[5] Thilagavany PK dan Santha A. The Achromatic and B-chromatic Number of Sun Graph, Barbel Graph and Some Named Graphs. International Journal of Pure and Applied Mathematics. 2017; 116: 147-155.

[6] Mary LJE dan Rayen ALMJ. On The Star coloring of Graph and Some Related Graphs. International Journal of Applications of Fuzzy Sets and Artifical Intelligence. 2016; 5: 23-25.

[7] Damayanti TR. Automorfisme Graf Bintang dan Graf Lintasan, Jurnal Cauchy. 2011; 2: 20860382

[8] Bibi KA dan Devi M. Fuzzy Bi-Magic Labelling on Cycle Graph and Star Graph. Global Journal of Pure and Applied Mathematics. 2017; 13: 1975-1985.

[9] Vaidya KS dan Isaac VR. The B-chromatic Number of Some Path Related Graphs. International Journal of Mathematics and Scientific Computing. 2014; 4: 2231-5330.

[10] Yesi I, Sudarsana W dan Musdalifah S. Pelabelan Total Tringular pada Beberapa Graf Pohon. Jurnal Ilmiah Matematika dan Terapan. 2016; 13: 17-24.

[11] Nabila S dan Salman ANM. The Rainbow Connection Number of Origami Graphs and Pizza Graphs. International Conference on Graph Theory and Information Security. 2015; 74: 162167.

[12] Kusmayadi TA dan Fatmawatie F. The eccentric Digraph of a Lintang Graph. Universitas Sebelas Maret. 2013; 57126.

[13] Bakhash KAP dan Al-Harere NM. Tadpole Domination in Graphs. Baghdad Science Journal. 2018; 15: 4.

PRANASARI KORNELIA : Jurusan Matematika FMIPA Untan, Pontianak, pranasariaza@gmail.com

EVI NOVIANI

: Jurusan Matematika FMIPA Untan, Pontianak, evi_noviani@math.untan.ac.id

FRANSISKUS FRAN : : Jurusan Matematika FMIPA Untan, Pontianak, fransiskusfran@math.untan.ac.id 